\title{
Cardiac characteristics and natural progression in Taiwanese patients with mucopolysaccharidosis III
}

\author{
Hsiang-Yu Lin 1,2,3,5,6, Ming-Ren Chen 1,2,4, Shan-Miao Lin ${ }^{1,2,4}$, Chung-Lieh Hung ${ }^{1,7}$, Dau-Ming Niü, \\ Tung-Ming Chang ${ }^{9,10}$, Chih-Kuang Chuang ${ }^{3,11^{*}}$ and Shuan-Pei Lin ${ }^{1,2,3,12^{*}}$
}

\begin{abstract}
Background: Mucopolysaccharidosis type III (MPS III), or Sanfilippo syndrome, is caused by a deficiency in one of the four enzymes involved in the lysosomal degradation of heparan sulfate. Cardiac abnormalities have been observed in patients with all types of MPS except MPS IX, however few studies have focused on cardiac alterations in patients with MPS III.

Methods: We reviewed medical records, echocardiograms, and electrocardiograms of 26 Taiwanese patients with MPS III (five with IIIA, 20 with IIIB, and one with IIIC; 14 males and 12 females; median age, 7.4 years; age range, 1.8-26.5 years). The relationships between age and each echocardiographic parameter were analyzed.

Results: Echocardiographic examinations $(n=26)$ revealed that 10 patients $(38 \%)$ had valvular heart disease. Four $(15 \%)$ and eight (31\%) patients had valvular stenosis or regurgitation, respectively. The most prevalent cardiac valve abnormality was mitral regurgitation (31\%), followed by aortic regurgitation (19\%). However, most of the cases of valvular heart disease were mild. Three (12\%), five (19\%) and five (19\%) patients had mitral valve prolapse, a thickened interventricular septum, and asymmetric septal hypertrophy, respectively. The severity of aortic regurgitation and the existence of valvular heart disease, aortic valve abnormalities and valvular stenosis were all positively correlated with increasing age $(p<0.05)$. $Z$ scores $>2$ were identified in $0,38,8$, and $27 \%$ of left ventricular mass index, interventricular septal end-diastolic dimension, left ventricular posterior wall end-diastolic dimension, and aortic diameter, respectively. Electrocardiograms in 11 patients revealed the presence of sinus arrhythmia $(n=3)$, sinus bradycardia $(n=2)$, and sinus tachycardia $(n=1)$. Six patients with MPS IIIB had follow-up echocardiographic data at 1.9-18.1 years to compare with the baseline data, which showed some patients had increased thickness of the interventricular septum, as well as more patients had valvular abnormalities at follow-up.

Conclusions: Cardiac involvement in MPS III is less common and milder compared with other types of MPS. The existence of valvular heart disease, aortic valve abnormalities and valvular stenosis in the patients worsened with increasing age, reinforcing the concept of the progressive nature of this disease.
\end{abstract}

Keywords: Cardiac, Echocardiography, Electrocardiography, Mucopolysaccharidosis III, Valvular heart disease

\footnotetext{
* Correspondence: mmhcck@gmail.com; linhy@mmh.org.tw

${ }^{3}$ Department of Medical Research, Mackay Memorial Hospital, 92

Chung-Shan N. Rd., Sec. 2, Taipei 10449, Taiwan

'Department of Medicine, Mackay Medical College, New Taipei City, Taiwan

Full list of author information is available at the end of the article
}

(C) The Author(s). 2019 Open Access This article is distributed under the terms of the Creative Commons Attribution 4.0 International License (http://creativecommons.org/licenses/by/4.0/), which permits unrestricted use, distribution, and

reproduction in any medium, provided you give appropriate credit to the original author(s) and the source, provide a link to the Creative Commons license, and indicate if changes were made. The Creative Commons Public Domain Dedication waiver (http://creativecommons.org/publicdomain/zero/1.0/) applies to the data made available in this article, unless otherwise stated. 


\section{Introduction}

Mucopolysaccharidoses (MPSs; OMIM 252700) comprise a group of lysosomal storage diseases resulting from deficiencies in specific lysosomal enzymes and involving the sequential degradation of glycosaminoglycans (GAGs), leading to substrate accumulation in various cells and tissues and progressive multi-organ dysfunction. Seven distinct types of MPS disorders (I, II, III, IV, VI, VII, and IX) with 11 specific lysosomal enzyme deficiencies have been reported [1]. The onset and severity of cardiovascular defects are different in each type of MPS, with the most recognized abnormalities being cardiac hypertrophy, cardiac valve thickening, and valvular regurgitation and stenosis [2-13]. Cardiomyopathy and valve defects result from GAG accumulation in the myocardium, cardiac valves, great vessels, and coronary arteries [14]. Deformities in cardiac structures may lead to cardiac dysfunction and mitral or aortic leaflet thickening and calcification resulting in valvular stenosis or regurgitation, which can significantly increase morbidity and mortality [15-18].

MPS III (Sanfilippo syndrome) includes four distinct diseases (types A-D) resulting from a deficiency in one of the four enzymes involved in heparan sulfate degradation as follows: heparan N-sulfatase in type A (OMIM 252900), alpha-N-acetylglucosaminidase (NAGLU) in type B (OMIM 252920), acetyl CoA-alpha-glucosaminide acetyltransferase in type C (OMIM 252930), and N-acetylglucosamine 6sulfatase in type D (OMIM 252940). MPS III has a variable age of onset and diverse rate of progression characterized by a large phenotypic heterogeneity. Patients with MPS III generally appear unaffected at birth, however clinical manifestations may emerge from 2 to 4 years of age, including intellectual disability, hyperactivity, coarse facial features with broad eyebrows, hirsutism, skeletal dysplasia, degenerative joint disease, hepatosplenomegaly, macrocephaly, and hearing loss [1, 19-21]. Cardiac abnormalities have been observed in patients with all types of MPS, except MPS IX [2$13]$, however only a few studies have focused on cardiac alterations in patients with MPS III [22-25]. A murine model of MPS IIIB (NAGLU knockout mice, NAGLU ${ }^{-/}$) demonstrated the development of abnormal valve morphology and function in an age-dependent manner associated with increased myocardial vacuolization, inflammation and fibrosis, as well as a dysregulated lysosomal autophagy in the cardiac tissues [26]. Unlike other MPS diseases, there is neither a satisfactory response to hematopoietic stem cell transplantation nor any available enzyme replacement therapy (ERT) for MPS III. With the development of new diseasemodifying treatments such as ERT and gene therapy, it is important to delineate the prevalence and severity of cardiac involvement in this patient population to identify any cardiac complications caused by these experimental therapies. The objective of this study was therefore to investigate the cardiac characteristics and natural progression of MPS III in Taiwanese patients to develop quality of care strategies.

\section{Materials and methods Study population}

The medical records, echocardiograms, and electrocardiograms of 26 Taiwanese patients with MPS III (five with IIIA, 20 with IIIB, and one with IIIC; 14 males and 12 females; median age, 7.4 years; age range, 1.8-26.5 years) were retrospectively reviewed at Mackay Memorial Hospital from July 1997 to October 2018. The diagnosis of MPS III was confirmed by measurements of enzymatic activities of particular lysosomal hydrolases in leukocytes or skin fibroblasts, two-dimensional electrophoresis of urinary GAGs, and/or mutational analysis, as well as the exclusion of multiple sulfatase deficiency by the detection of normal enzymatic activities of other lysosomal hydrolases [27, 28]. Six patients with MPS III who had follow-up echocardiographic data at 1.9-18.1 years were also reviewed. The relationships between age and each echocardiographic parameter were analyzed. None of the patients received ERT or a hematopoietic stem cell transplantation during the study period. Written informed consent for cardiac evaluations was obtained from a parent for children and from the patients if they were over 18 years of age. The study was approved by the Ethics Committee of Mackay Memorial Hospital, Taipei, Taiwan.

\section{Measurements of echocardiographic parameters}

We used a Philips Sonos 5500/7500 ultrasound system (Andover, MA, USA) equipped with electronic transducers from 2 to $8 \mathrm{MHz}$. Data were digitally stored and analyzed by one experienced cardiologist (MRC) to minimize inter-observer variations. Diastolic and systolic diameters were measured using M-mode and two-dimensional echocardiography. The systolic function of the left ventricle was assessed on the basis of the ejection fraction according to the Simpson method. For children, an ejection fraction $<50 \%$ was considered abnormal. For adults, an abnormal ejection fraction was defined as $<52 \%$ for men and $<54 \%$ for women [29]. A shortening fraction $<28 \%$ was deemed to be abnormal. Asymmetric septal hypertrophy (ASH) was considered present if left ventricular (LV) interventricular septum/posterior wall thickness ratio in end-diastole $\geq 1.5$ [30]. Diastolic filling was estimated using the E/A ratio by measuring mitral-inflow according to pattern-peak early filling (E) and late filling (A) velocities, and systolic function was assessed using the shortening fraction [31]. A reversed $\mathrm{E} / \mathrm{A}$ ratio $(\mathrm{E} / \mathrm{A}$ ratio $<1)$ was considered to indicate diastolic dysfunction. The severity of valvular stenosis and regurgitation was assessed and graded as follows: 0 (none), 1 (mild), 2 (moderate), and 3 (severe) based on the European Society of Cardiology 
guidelines [10-12, 32, 33]: mild aortic stenosis $(\mathrm{AS})=$ valve area $>1.5 \mathrm{~cm}^{2}$ and mean gradient $<30 \mathrm{mmHg}$; moderate AS = valve area between $1.0-1.5 \mathrm{~cm}^{2}$ and mean gradient between 30 and $50 \mathrm{mmHg}$; severe AS = valve area < $1.0 \mathrm{~cm}^{2}$ and mean gradient $>50 \mathrm{mmHg}$; mild mitral stenosis $(\mathrm{MS})=$ valve area $>1.5 \mathrm{~cm}^{2}$ and mean gradient $<5$ $\mathrm{mmHg}$; moderate $\mathrm{MS}=$ valve area between $1.0-1.5 \mathrm{~cm}^{2}$ and mean gradient between 5 and $10 \mathrm{mmHg}$; severe $\mathrm{MS}=$ valve area $<1.0 \mathrm{~cm}^{2}$ and mean gradient $>10 \mathrm{mmHg}$. As the frequency of physiological tricuspid regurgitation is high in the general population, including the pediatric population, we did not categorize tricuspid regurgitation into pathological findings in this study.

We recorded data on left ventricular mass index (LVMI), right ventricular end-diastolic dimension (RVDd), interventricular septal end-diastolic dimension (IVSd) and end-systolic (IVSs), left ventricular enddiastolic dimension (LVIDd) and end-systolic (LVIDs), left ventricular posterior wall end-diastolic dimension (LVPWd) and end-systolic (LVPWs), aortic diameter, and left atrial dimension (LAD) acquired by echocardiographic evaluations. Relative wall thickness was calculated as $(2 \times$ LVPWd $) / L V I D d$. Concentric remodeling was defined as normal LV mass with relative wall thickness $>0.42$ [34]. Measurements of the aorta were made on the sinus from leading edge to leading edge. These values were compared with normal values based on the study of Kampmann et al. [35]. LVMI was computed using the Devereux formula and indexed by height $z$ score with normal values according to the report of Foster et al. [36]. All of the aforementioned echocardiographic parameters were transformed into a $z$ score derived by subtracting the mean reference value from an individual observed value, and then dividing the difference by the standard deviation from the reference value. A $z$ score between -2 and +2 was considered to be normal. In addition, 11 patients also had available electrocardiographic (ECG) data. The pediatric values were used as a reference for children.

\section{Data analysis and statistics}

Sex, age, height, weight, and body surface area at the time of echocardiographic assessments were recorded for each patient. Descriptive statistics including means and standard deviations of all echocardiographic parameters were computed. The relationships between age and different echocardiographic parameters were established using Pearson's correlation coefficient $(r)$, and significance was tested using Fisher's $r-z$ transformations. Two-tailed $p$-values were calculated. All statistical analyses were carried out using SPSS version 11.5 (SPSS Inc., Chicago, Illinois, USA). Differences with $p<0.05$ were considered to be statistically significant.

\section{Results}

Tables 1 and 2 show the baseline clinical, echocardiographic and electrocardiographic characteristics of the 26 patients with MPS III. Echocardiographic examinations $(n=26)$ revealed that 10 patients $(38 \%)$ had valvular heart disease. Four (15\%) and eight (31\%) patients had valvular stenosis or regurgitation, respectively (Table 3 ). The most prevalent cardiac valve abnormality was mitral regurgitation (MR) (31\%), followed by aortic regurgitation (AR) (19\%) (Table 4). However, most cases of valvular heart disease were mild. No one under the age of 4.8 years had valvular stenosis (Fig. 1). Three (12\%), five (19\%) and five (19\%) patients had mitral valve prolapse, a thickened interventricular septum, and ASH, respectively. The severity of aortic regurgitation and the existence of valvular heart disease, aortic valve abnormalities and valvular stenosis were all positively correlated with increasing age $(p<0.05)$ (Tables 3 and 4). The mean $z$ scores of LVMI, IVSd, LVPWd, and aortic diameter were - 0.36, 1.71, 0.15 and 1.62 , respectively. $Z$ scores $>2$ were identified in $0,38,8$, and $27 \%$ of LVMI, IVSd, LVPWd, and aortic diameter, respectively (Table 5$)$. Four patients (15\%) had left ventricular concentric remodeling (LVMI $z$ score $<2$ and relative wall thickness $>0.42)$, and the other 22 patients $(85 \%)$ had normal LV geometry. E/A ratio $<1$ was identified in one patient (4\%), however, the ejection fraction and shortening fraction values were normal and revealed no substantial systolic dysfunction. Electrocardiograms in 11 patients revealed the presence of sinus arrhythmia $(n=3)$, sinus bradycardia $(n=2)$, and sinus tachycardia $(n=1)$. The ECG abnormalities were usually of minor clinical significance (Tables 1 and 2). Six patients with MPS IIIB (baseline age range, 1.8 to 5.2 years) had follow-up echocardiographic data at 1.9-18.1 years to compare with the baseline data, and the results showed a change in mean LVMI $z$ score from -0.39 to 0.59 , an increase in mean IVSd $z$ score from 1.32 to 3.36 , a change in mean LVPWd $z$ score from 0.13 to 0.24 , and changes in mean severity $z$ scores of MS, MR, AS, and AR from 0 to $0.5,0.2$ to $0.7,0$ to 0.2 , and 0 to 0 , respectively (Tables 6 and 7).

\section{Discussion}

As far as we are aware, this is the first study to delineate the cardiac structure and function and natural progression of MPS III in Asian patients and compare them with normal values obtained from a population that included young adults on the basis of the report of Kampmann et al. [35]. Compared with the other types of MPS diseases, cardiac involvement in MPS III has received relatively little attention [22-25]. Our results demonstrated that most of the patients with MPS III had mild valvular heart disease, and some had aortic dilatation and increased thickness of the interventricular septum. We found an increase in IVSd, however, no increase in 
LVMI. IVSd is part of the LVMI. The clinical relevance of an isolated increased IVSd might be due to LV remodeling pattern of these patients. In this cohort, four patients (15\%) had LV concentric remodeling defined as normal LV mass with relative wall thickness $>0.42$ [34]. The valvular stenosis in these patients worsened with increasing age, in accordance with the progressive nature of this disease. For the six patients with MPS IIIB who had follow-up echocardiographic data at 1.9-18.1 years, echocardiography showed some patients had increased thickness of the interventricular septum, as well as more patients had valvular abnormalities at followup. Our results are consistent with those of a previous study in a Caucasian population [22].

Cardiac involvement in MPS III has been reported to be less common and milder compared with the other types of MPS [2, 10, 20-23, 37]. Nijmeijer et al. [23] reported mitral valve abnormalities and aortic valve abnormalities in $13 / 30(43 \%)$ and 10/30 (33\%) patients with MPS III, respectively. Consistently, echocardiographic examinations in our cohort also revealed that 35 and $27 \%$ of the patients had mitral valve abnormalities or aortic valve abnormalities, respectively. In this study, $38 \%$ of the MPS III patients had valvular heart disease, however most of the cases had mild disease, and no one under the age of 4.8 years had valvular stenosis.

Echocardiographic assessments revealed mean $z$ scores of LVMI, IVSd, LVPWd, and aortic diameter of -0.36 , $1.71,0.15$ and 1.62 , respectively, and $\mathrm{z}$ scores $>2$ were identified in $0,38,8$, and $27 \%$ of LVMI, IVSd, LVPWd, and aortic diameter, respectively. Bolourchi et al. [38] reported that patients with MPS III had a high prevalence of aortic root dilatation $(3 / 6,50 \%)$, which is consistent with our results $(7 / 26,27 \%)$. Although LV systolic

Table 1 Baseline clinical and echocardiographic features of the 26 patients with MPS III

\begin{tabular}{|c|c|c|c|c|c|c|c|c|c|c|c|c|c|c|c|c|}
\hline$\overline{\text { No. }}$ & Gender & $\begin{array}{l}\text { MPS } \\
\text { type }\end{array}$ & $\begin{array}{l}\text { Age } \\
\text { (years) }\end{array}$ & $\begin{array}{l}\text { LVMI (z } \\
\text { score) }\end{array}$ & $\begin{array}{l}\text { RVDd (z } \\
\text { score) }\end{array}$ & $\begin{array}{l}\text { IVSd (z } \\
\text { score) }\end{array}$ & $\begin{array}{l}\text { IVSs (z } \\
\text { score) }\end{array}$ & $\begin{array}{l}\text { LVIDd (z } \\
\text { score) }\end{array}$ & $\begin{array}{l}\text { LVIDs (z } \\
\text { score) }\end{array}$ & $\begin{array}{l}\text { LVPWd } \\
\text { (z score) }\end{array}$ & $\begin{array}{l}\text { LVPWs } \\
\text { (z score) }\end{array}$ & $\begin{array}{l}\text { AoD (z } \\
\text { score) }\end{array}$ & $\begin{array}{l}\text { LAD (z } \\
\text { score) }\end{array}$ & $\begin{array}{l}\mathrm{EF} \\
(\%)\end{array}$ & $\begin{array}{l}\text { SF } \\
(\%)\end{array}$ & $\begin{array}{l}\text { Reversed } \\
\text { E/A ratio }\end{array}$ \\
\hline 1 & $M$ & $\| I I B$ & 1.8 & -0.98 & 3.20 & 4.08 & 1.08 & -2.15 & -1.86 & -0.48 & -0.12 & 0.62 & 0.14 & $62 \%$ & $39 \%$ & - \\
\hline 2 & M & $\| \mathrm{II}$ & 2.2 & -0.51 & 0.67 & 0.44 & 0.53 & 0.70 & 0.00 & -0.43 & 0.44 & 1.38 & 0.14 & $73 \%$ & $41 \%$ & - \\
\hline 3 & $\mathrm{~F}$ & $\| \mathrm{A} A$ & 3.6 & 0.10 & 2.73 & 4.07 & 0.85 & -2.22 & -0.85 & 2.86 & 0.48 & 2.53 & 1.68 & $57 \%$ & $28 \%$ & - \\
\hline 4 & $M$ & $\| \mathrm{II}$ & 4.2 & 0.44 & -1.50 & 2.07 & 0.41 & 0.83 & -0.04 & -0.19 & -0.88 & -0.53 & -1.28 & $74 \%$ & $42 \%$ & - \\
\hline 5 & $M$ & $\| I B$ & 4.3 & -0.58 & NA & -0.11 & NA & 0.62 & 0.14 & -0.73 & NA & 1.83 & -0.06 & $69 \%$ & $38 \%$ & - \\
\hline 6 & $\mathrm{~F}$ & $\| \mathrm{I} B$ & 4.9 & -1.73 & 1.50 & 2.29 & -0.17 & -1.20 & -0.88 & -0.85 & -0.66 & 0.65 & -0.88 & $57 \%$ & $37 \%$ & - \\
\hline 7 & M & $\| \mathrm{IIB}$ & 5.1 & -2.31 & -0.05 & -1.25 & -0.24 & 0.14 & -2.13 & -0.87 & -0.25 & 0.71 & -0.55 & $85 \%$ & $53 \%$ & - \\
\hline 8 & M & $\| \mathrm{IIB}$ & 5.1 & 0.19 & -0.60 & 0.90 & 1.18 & 1.97 & 1.07 & -0.57 & -0.25 & 2.39 & -0.39 & $54 \%$ & $38 \%$ & - \\
\hline 9 & $\mathrm{~F}$ & $\| \mathrm{IIB}$ & 5.2 & 0.02 & 1.19 & 0.65 & 0.33 & 0.13 & -1.60 & 0.02 & -0.75 & 1.35 & -0.17 & $81 \%$ & $48 \%$ & - \\
\hline 10 & $\mathrm{~F}$ & $\| \mathrm{I} B$ & 5.2 & 0.28 & 1.45 & 1.47 & 0.54 & -0.68 & -2.92 & 2.86 & 0.64 & 1.47 & 0.36 & $88 \%$ & $57 \%$ & - \\
\hline 11 & M & $\| \mathrm{II}$ & 5.4 & 1.21 & 0.00 & 4.13 & 0.35 & -0.07 & 0.64 & 0.42 & 1.11 & 0.67 & -0.39 & $60 \%$ & $31 \%$ & - \\
\hline 12 & $\mathrm{~F}$ & $\| \mathrm{II}$ & 6.0 & -0.82 & 1.87 & 1.31 & -1.14 & -0.07 & 0.64 & -1.13 & -1.39 & -0.28 & 2.10 & $60 \%$ & $31 \%$ & - \\
\hline 13 & M & $\| \mathrm{I} B$ & 7.2 & 0.36 & 1.875 & 2.63 & 1.33 & 0.41 & -0.28 & -0.69 & 2.59 & 0.61 & -0.34 & $72 \%$ & $41 \%$ & - \\
\hline 14 & M & $\||| B$ & 7.5 & 0.58 & 1.65 & 3.24 & 0.78 & -0.89 & -0.79 & 1.38 & -0.93 & 0.72 & 0.90 & $59 \%$ & $38 \%$ & - \\
\hline 15 & M & $\| \mathrm{IIB}$ & 7.8 & 1.10 & 1.29 & 2.00 & -0.48 & 1.26 & 1.38 & 0.52 & -0.79 & 2.83 & -1.03 & $54 \%$ & $34 \%$ & - \\
\hline 16 & M & $\| \mathrm{II}$ & 9.9 & -1.54 & -1.28 & -1.04 & -0.15 & 1.44 & 0.04 & -1.51 & -0.76 & 1.83 & 1.26 & $74 \%$ & $43 \%$ & - \\
\hline 17 & $F$ & $\| \mathrm{IIB}$ & 10.5 & -0.40 & NA & 1.37 & NA & -0.03 & -0.61 & 0.75 & NA & 1.88 & -0.60 & $72 \%$ & $40 \%$ & - \\
\hline 18 & $\mathrm{~F}$ & $\| \mathrm{A}$ & 11.0 & -1.61 & 0.96 & 2.44 & 0.90 & -1.51 & -0.68 & -0.44 & -1.26 & 0.56 & -1.35 & $63 \%$ & $33 \%$ & - \\
\hline 19 & $\mathrm{~F}$ & $\| \mathrm{II}$ & 11.4 & 0.50 & NA & 5.56 & 0.83 & -1.52 & -0.57 & 0.31 & -0.13 & 2.86 & -1.57 & $60 \%$ & $31 \%$ & - \\
\hline 20 & $\mathrm{~F}$ & $\| \mathrm{IIB}$ & 11.5 & -0.09 & -0.09 & 0.11 & 0.04 & 0.55 & -0.89 & 0.43 & 1.27 & 0.06 & 0.63 & $77 \%$ & $45 \%$ & - \\
\hline 21 & $\mathrm{~F}$ & $\||| B$ & 12.3 & -1.48 & 2.04 & 2.03 & 0.56 & -0.12 & -0.38 & -1.13 & -0.44 & 3.56 & -0.72 & $70 \%$ & $39 \%$ & - \\
\hline 22 & $\mathrm{~F}$ & $\| \mathrm{B}$ & 12.9 & -1.60 & NA & 0.11 & NA & -1.74 & -2.32 & 0.38 & NA & 1.26 & -2.75 & $75 \%$ & $43 \%$ & - \\
\hline 23 & $M$ & IIIA & 13.6 & 0.50 & NA & 0.91 & NA & 0.97 & -0.20 & 0.36 & NA & 1.74 & -1.52 & $73 \%$ & $42 \%$ & - \\
\hline 24 & M & $\| \mathrm{II}$ & 16.4 & -0.20 & NA & 2.00 & NA & 0.00 & -0.25 & 0.92 & NA & 5.19 & -4.29 & $68 \%$ & $38 \%$ & - \\
\hline 25 & $\mathrm{~F}$ & $\| \mathrm{BB}$ & 18.5 & 0.23 & NA & 1.33 & NA & 1.62 & 1.24 & 1.73 & NA & 6.17 & -0.34 & $66 \%$ & $36 \%$ & + \\
\hline 26 & M & IIIC & 26.5 & -1.13 & -1.76 & 1.74 & 0.23 & 0.00 & 0.54 & 0.04 & -1.71 & 0.12 & -0.44 & $63 \%$ & $33 \%$ & - \\
\hline
\end{tabular}

MPS Mucopolysaccharidosis, LVMI Left ventricular mass index, RVDd Right ventricular end-diastolic dimension, IVSd Interventricular septal end-diastolic dimension, IVSs Interventricular septal end-systolic dimension, LVIDd Left ventricular end-diastolic dimension, LVIDs Left ventricular end-systolic dimension, LVPWd Left ventricular posterior wall end-diastolic dimension, $L V P W s$ Left ventricular posterior wall end-systolic dimension, $A o D$ Aortic diameter, $L A D$ Left atrial dimension, $E F$ Ejection fraction, SF Shortening fraction, E/A Ratio between early and late (atrial) ventricular filling velocity, NA Not available The abnormal values ( $\mathrm{z}$ score $>2$ or $<-2$ ) are presented in boldface 
Table 2 Baseline clinical, echocardiographic and electrocardiographic features of the 26 patients with MPS III

\begin{tabular}{|c|c|c|c|c|c|c|c|c|c|c|c|c|}
\hline No. & Gender & $\begin{array}{l}\text { MPS } \\
\text { type }\end{array}$ & $\begin{array}{l}\text { Age } \\
\text { (years) }\end{array}$ & MS & MR & AS & $A R$ & MVP & $\begin{array}{l}\text { Thick } \\
\text { IVS }\end{array}$ & ASH & $\begin{array}{l}\text { Left ventricular remodeling } \\
\text { pattern }\end{array}$ & Electrocardiographic features \\
\hline 1 & $M$ & $\mathrm{IIIB}$ & 1.8 & 0 & 0 & 0 & 0 & - & + & + & Concentric remodeling & Normal \\
\hline 2 & M & $\| \mathrm{B}$ & 2.2 & 0 & 0 & 0 & 0 & - & - & - & Normal & Normal \\
\hline 3 & $\mathrm{~F}$ & IIIA & 3.6 & 0 & 0 & 0 & 0 & - & + & - & Concentric remodeling & NA \\
\hline 4 & M & $\| \mathrm{B}$ & 4.2 & 0 & 0 & 0 & 0 & - & - & - & Normal & Normal \\
\hline 5 & M & $\| \mathrm{B}$ & 4.3 & 0 & 0 & 0 & 0 & - & - & - & Normal & Sinus bradycardia, sinus arrhythmia \\
\hline 6 & $\mathrm{~F}$ & $\| \mathrm{B}$ & 4.9 & 0 & 1 & 1 & 0 & - & - & + & Normal & $\begin{array}{l}\text { Normal sinus rhythm, borderline } \\
\text { QTC }\end{array}$ \\
\hline 7 & M & $\| \mathrm{B}$ & 5.1 & 0 & 0 & 0 & 0 & - & - & - & Normal & NA \\
\hline 8 & M & $\| \mathrm{B}$ & 5.1 & 0 & 0 & 0 & 0 & - & - & - & Normal & NA \\
\hline 9 & $\mathrm{~F}$ & $\| \mathrm{B}$ & 5.2 & 0 & 0 & 0 & 0 & - & - & - & Normal & Sinus arrhythmia \\
\hline 10 & $\mathrm{~F}$ & $\| \mathrm{B}$ & 5.2 & 0 & 1 & 0 & 0 & + & - & - & Normal & Sinus tachycardia \\
\hline 11 & M & $\| \mathrm{B}$ & 5.4 & 0 & 0 & 0 & 0 & - & - & - & Normal & NA \\
\hline 12 & $\mathrm{~F}$ & $\| \mathrm{II}$ & 6.0 & 0 & 0 & 0 & 0 & + & - & - & Normal & NA \\
\hline 13 & M & $\| \mathrm{B}$ & 7.2 & 1 & 0 & 0 & 0 & - & + & + & Normal & NA \\
\hline 14 & M & $\| \mathrm{B}$ & 7.5 & 0 & 0 & 0 & 0 & + & - & - & Concentric remodeling & NA \\
\hline 15 & M & $\| \mathrm{B}$ & 7.8 & 0 & 0 & 0 & 0 & - & + & - & Normal & NA \\
\hline 16 & M & IIIA & 9.9 & 0 & 0 & 0 & 0 & - & - & - & Normal & Sinus arrhythmia \\
\hline 17 & $\mathrm{~F}$ & $\| \mathrm{B}$ & 10.5 & 0 & 1 & 0 & 2 & - & - & - & Normal & NA \\
\hline 18 & $\mathrm{~F}$ & $\| \mathrm{A}$ & 11.0 & 0 & 1 & 0 & 0 & - & - & - & Normal & NA \\
\hline 19 & $\mathrm{~F}$ & $\| \mathrm{B}$ & 11.4 & 0 & 0 & 0 & 0 & - & + & + & Concentric remodeling & NA \\
\hline 20 & $\mathrm{~F}$ & $\| \mathrm{B}$ & 11.5 & 0 & 0 & 0 & 1 & - & - & - & Normal & NA \\
\hline 21 & $\mathrm{~F}$ & $\| \mathrm{B}$ & 12.3 & 0 & 0 & 0 & 0 & - & - & + & Normal & Sinus bradycardia, short PR interval \\
\hline 22 & $\mathrm{~F}$ & $\| \mathrm{B}$ & 12.9 & 0 & 0.5 & 0 & 0.5 & - & - & - & Normal & NA \\
\hline 23 & M & $\| \mathrm{A}$ & 13.6 & 0 & 1 & 0 & 3 & - & - & - & Normal & NA \\
\hline 24 & M & $\| \mathrm{A}$ & 16.4 & 0 & 0.5 & 0 & 0 & - & - & - & Normal & NA \\
\hline 25 & $\mathrm{~F}$ & $\||| B$ & 18.5 & 1 & 1 & 0 & 2 & - & - & - & Normal & Normal \\
\hline 26 & M & $I I I C$ & 26.5 & 0 & 0 & 1 & 0 & - & - & - & Normal & Normal \\
\hline
\end{tabular}

MPS Mucopolysaccharidosis, MS Mitral stenosis, MR Mitral regurgitation, AS Aortic stenosis, AR Aortic regurgitation, MVP Mitral valve prolapse, IVS Interventricular septum, ASH Asymmetric septal hypertrophy, NA Not available. Severity of valvular stenosis and regurgitation (MS, MR, AS, AR) were estimated and graded on the following scores: 0 (none), 1 (mild), 2 (moderate), and 3 (severe)

function according to ejection fraction and shortening fraction values was normal in all of our patients, however, ejection fraction and shortening fraction values are parameters that show abnormalities when there is substantial LV dysfunction. Speckle-tracking echocardiography is a marker for early, subclinical LV dysfunction which was recently reported in patients with MPS III by Nijmeijer et al. [23]. In our study, a reversed E/A ratio $(<1)$ was identified in one patient $(4 \%)$. However, an abnormal mitral valve E/A ratio could also be attributed to mitral valve abnormalities. This patient (No. 25) with the abnormal E/A ratio also had mitral valve abnormalities. Thus this could not definitely be attributed to diastolic

Table 3 Echocardiographic features of the 26 patients with MPS III and the relationships between cardiac valve abnormalities and age

\begin{tabular}{|c|c|c|c|c|c|}
\hline Cardiac valve abnormalities & $\begin{array}{l}\text { Valvular heart } \\
\text { disease }\end{array}$ & $\begin{array}{l}\text { Valvular } \\
\text { stenosis }\end{array}$ & $\begin{array}{l}\text { Valvular } \\
\text { regurgitation }\end{array}$ & $\begin{array}{l}\text { Mitral valve } \\
\text { abnormality }\end{array}$ & $\begin{array}{l}\text { Aortic valve } \\
\text { abnormality }\end{array}$ \\
\hline n (\%) & $10(38 \%)$ & $4(15 \%)$ & $8(31 \%)$ & $9(35 \%)$ & $7(27 \%)$ \\
\hline $\begin{array}{l}r \text { value (cardiac valve abnormalities versus } \\
\text { age) }\end{array}$ & 0.554 & 0.419 & 0.343 & 0.302 & 0.572 \\
\hline$p$ value & $p<0.01$ & $p<0.05$ & $p>0.05$ & $p>0.05$ & $p<0.01$ \\
\hline
\end{tabular}

MPS Mucopolysaccharidosis

$p$ value $<0.05$ and $p$ value $<0.01$ are presented in boldface 
Table 4 Echocardiographic features of the 26 patients with MPS III and the relationships between severity of cardiac valve abnormalities and age

\begin{tabular}{|c|c|c|c|c|c|c|}
\hline Echocardiographic features & MS & MR & AS & $A R$ & MVP & Thick IVS \\
\hline n (\%) & $2(8 \%)$ & $8(31 \%)$ & $2(8 \%)$ & $5(19 \%)$ & $3(12 \%)$ & $5(19 \%)$ \\
\hline$r$ value (severity of cardiac valve abnormalities versus age) & 0.211 & 0.272 & 0.357 & 0.375 & -0.171 & -0.218 \\
\hline$p$ value & $p>0.05$ & $p>0.05$ & $p>0.05$ & $p<0.05$ & $p>0.05$ & $p>0.05$ \\
\hline
\end{tabular}

MPS Mucopolysaccharidosis, MS Mitral stenosis, MR Mitral regurgitation, AS Aortic stenosis, AR Aortic regurgitation, MVP Mitral valve prolapse, IVS Interventricular septum

$p$ value $<0.05$ is presented in boldface

dysfunction. Previous studies have indicated that abnormal catabolism of dermatan sulfate in patients with MPS I, II and VI results in the accumulation of dermatan-sulfated GAGs in cardiac valves, leading to valvular thickening and other cardiac defects $[6,7]$. The main storage products of MPS III is heparan sulfate, which has been reported to potentially be an essential constituent of life-long cardiac conduction system plasticity and that its storage results in atrioventricular block [39]. Cardiac lesions may be less prominent in MPS III than in MPS I, II, and VI [37]. Aortic dilatation and increased interventricular septum thickness, as well as valvular stenosis and regurgitation were still present in some of our patients, and the severity of aortic regurgitation also worsened with increasing age.

There were varying degrees of valvular deformities in our patients, although most had mild stenosis or regurgitation. Valvular regurgitation (31\%) was more common than valvular stenosis (15\%) in our cohort, which is consistent with the study of Wilhelm et al. [22]. They also reported that leftsided valves were much more commonly involved than right-sided valves in patients with MPS III. In our study, the most prevalent cardiac valve abnormality was MR (31\%), followed by AR (19\%). In relation to grade 1 MR, Kampmann et al. [40] described that it was a common finding in the pediatric population in their experience, thus they did not consider MR grade 1 in their study results of valve abnormalities in MPS II. However, in the few original studies focusing on cardiac alterations in patients with MPS III by Wilhelm et al. [22] and Nijmeijer et al. [23], they both reported the findings of grade $1 \mathrm{MR}$ in their results. Our report was consistent with the latter studies.

Ventricular remodeling indicates alterations in ventricular architecture with associated increases in volume and altered chamber configuration leading to myocyte hypertrophy and apoptosis, myofibroblast proliferation, and interstitial fibrosis [41]. Few reports have described

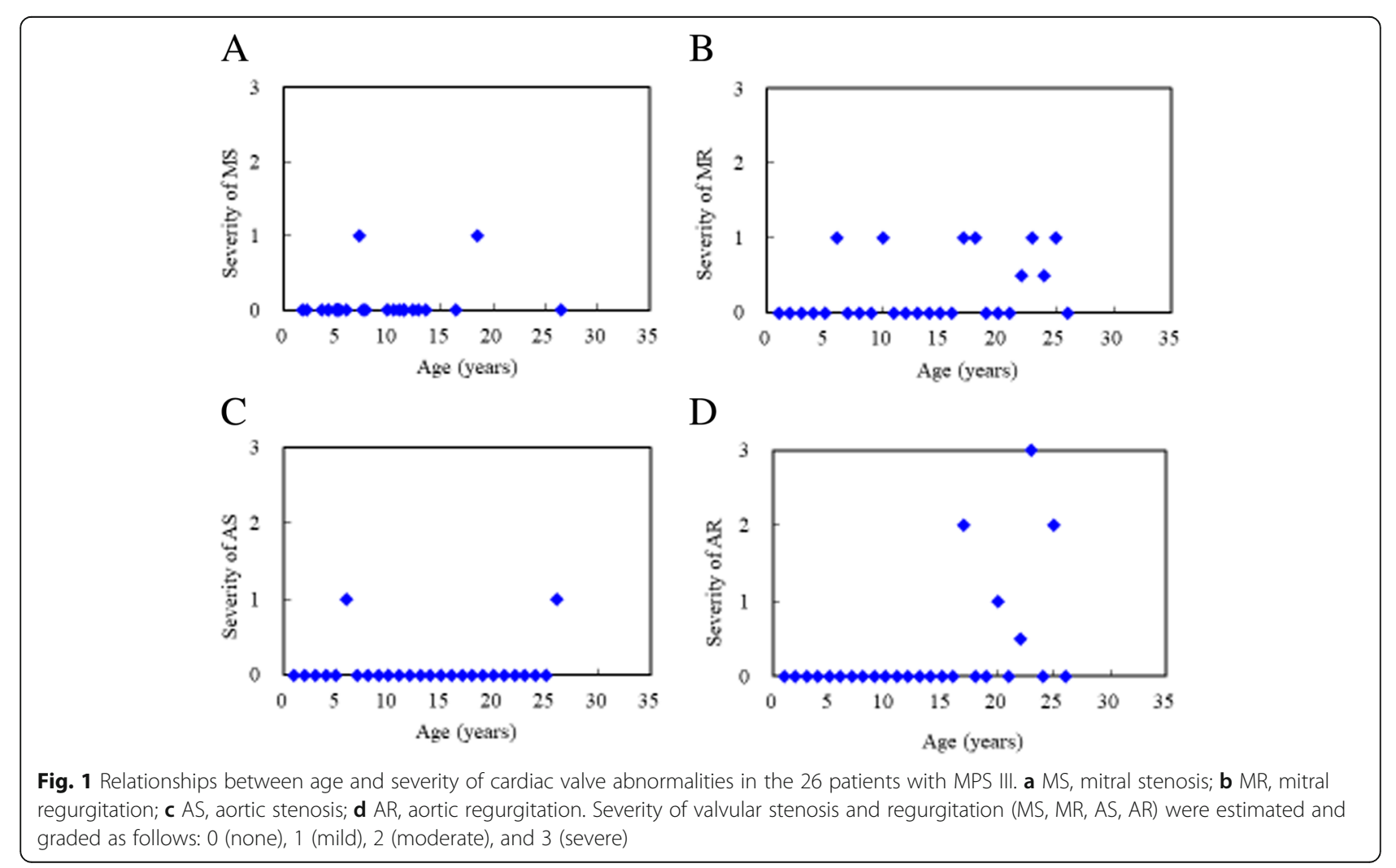


Table 5 The values of echocardiographic parameters of the 26 patients with MPS III

\begin{tabular}{|c|c|c|c|c|c|c|c|c|c|c|}
\hline $\begin{array}{l}\text { Echocardiographic } \\
\text { parameters }\end{array}$ & $\begin{array}{l}\text { LVMI ( } z \\
\text { score) }\end{array}$ & $\begin{array}{l}\text { RVDd ( } z \\
\text { score) }\end{array}$ & $\begin{array}{l}\text { IVSd ( } z \\
\text { score) }\end{array}$ & $\begin{array}{l}\text { IVSs ( } z \\
\text { score) }\end{array}$ & $\begin{array}{l}\text { LVIDd ( } z \\
\text { score) }\end{array}$ & $\begin{array}{l}\text { LVIDs (z } \\
\text { score) }\end{array}$ & $\begin{array}{l}\text { LVPWd ( } \\
\text { score) }\end{array}$ & $\begin{array}{l}\text { LVPWs ( } z \\
\text { score) }\end{array}$ & $\begin{array}{l}\text { AoD (z } \\
\text { score) }\end{array}$ & $\begin{array}{l}\operatorname{LAD}(z \\
\text { score })\end{array}$ \\
\hline Mean & -0.36 & 0.80 & 1.71 & 0.39 & -0.06 & -0.44 & 0.15 & -0.19 & 1.62 & -0.44 \\
\hline SD & 0.94 & 1.41 & 1.62 & 0.61 & 1.15 & 1.09 & 1.12 & 1.03 & 1.57 & 1.31 \\
\hline Z score > 2 (\%) & $0 \%$ & $16 \%$ & $38 \%$ & $0 \%$ & $0 \%$ & $0 \%$ & $8 \%$ & $5 \%$ & $27 \%$ & $4 \%$ \\
\hline
\end{tabular}

MPS Mucopolysaccharidosis, LVMI Left ventricular mass index, RVDd Right ventricular end-diastolic dimension, IVSd Interventricular septal end-diastolic dimension, IVSs Interventricular septal end-systolic dimension, LVIDd Left ventricular end-diastolic dimension, LVIDs Left ventricular end-systolic dimension, LVPWd Left ventricular posterior wall end-diastolic dimension, $L V P W$ s Left ventricular posterior wall end-systolic dimension, $A o D$ Aortic diameter, $L A D$ Left atrial dimension, $S D$ Standard deviation

the LV remodeling pattern in patients with MPS. In our study, four patients (15\%) had LV concentric remodeling associated with a higher risk of subsequent cardiovascular events compared to the other 22 patients (85\%) with normal LV geometry.

Forty-five percent of our ECGs showed specific findings, including sinus arrhythmia (3/11, 27\%), sinus bradycardia $(n=2)$, and sinus tachycardia $(n=1)$ although the clinical significance was minor. However, a respiratory arrhythmia is common amongst children. Thus these findings did not have to be pathological. Sudden and unexpected death due to heart block has been reported in isolated case reports of adults with MPS II, III and VI [13, 39]. Although ECG has been reported to be an unreliable tool for detecting cardiologic defects in MPS [9], due to the rapidity and easy accessibility of this inexpensive diagnostic tool, we still suggest that ECG should remain part of the follow-up examinations of patients with MPS III, especially to identify rhythm abnormalities or changes in conduction.

ERT for other MPS diseases appears to be effective in stabilizing or reducing cardiac hypertrophy, and better results may be associated with starting ERT at a younger age. There is no sufficient evidence to state an effect of ERT on valvulopathy. Some reports might show that ERT appears to diminish deterioration of already developed valvular heart disease [11, 12, 42], however, some studies report deterioration of valvulopathy or an increase in number of patients with valvulopathy after ERT [9, 14]. Further studies are needed to elucidate whether successful gene therapy can lead to similar cardiac outcomes. Due to the progressive nature of MPS, initiating ERT or gene therapy before the occurrence of irreversible cardiac damage may contribute to a better clinical outcome. Thus, making an early diagnosis through screening programs for high-risk populations or newborns is very important [43-46].

\section{Limitations}

As a retrospective and uncontrolled study, there was no healthy control group to compare the echocardiographic parameters with those of our patients. Not all of the patients in this cohort had follow-up echocardiographic data to compare with baseline data. We used the reference values from the Caucasian population due to the lack of those from the Asian population. Although the patients in this cohort were included from 1997 and onwards, all the images from echocardiographs from 1997 had sufficient quality with reliable and reproducible measurement. The small sample size of patients with MPS III reflects the rare nature of this genetic disorder. In addition, both the degree of disease severity and age range (1.8-26.5 years) varied considerably. As a result, studies with larger cohorts and longer follow-up periods are warranted.

Table 6 Six patients with MPS IIIB who had follow-up echocardiographic examinations after 1.9-18.1 years of follow-up compared with the baseline data

\begin{tabular}{|c|c|c|c|c|c|c|c|c|c|c|c|c|c|}
\hline \multirow{2}{*}{$\begin{array}{l}\text { MPS } \\
\text { type }\end{array}$} & \multirow[t]{2}{*}{ Gender } & \multirow{2}{*}{$\begin{array}{l}\text { Age at } \\
\text { baseline } \\
\text { (years) }\end{array}$} & \multirow{2}{*}{$\begin{array}{l}\text { Age at } \\
\text { follow- } \\
\text { up } \\
\text { (years) }\end{array}$} & \multirow{2}{*}{$\begin{array}{l}\text { Duration } \\
\text { (years) }\end{array}$} & \multicolumn{2}{|c|}{ LVMI (z score) } & \multirow{2}{*}{$\begin{array}{l}\text { Change } \\
\text { (z score) }\end{array}$} & \multicolumn{2}{|c|}{ IVSd (z score) } & \multirow{2}{*}{$\begin{array}{l}\text { Change } \\
\text { (z score) }\end{array}$} & \multicolumn{2}{|c|}{ LVPWd (z score) } & \multirow{2}{*}{$\begin{array}{l}\text { Change } \\
\text { (z score) }\end{array}$} \\
\hline & & & & & Baseline & Follow-up & & Baseline & Follow-up & & Baseline & Follow-up & \\
\hline IIIB & $F$ & 5.2 & 23.3 & 18.1 & 0.02 & 0.99 & 0.97 & 0.65 & 8.11 & 7.46 & 0.02 & -0.19 & -0.21 \\
\hline$\| I \mid B$ & $F$ & 5.2 & 23.3 & 18.1 & 0.28 & 1.06 & 0.78 & 1.47 & 3.32 & 1.86 & 2.86 & 0.80 & -2.06 \\
\hline IIIB & $M$ & 5.1 & 7.8 & 2.7 & -2.31 & -0.16 & 2.15 & -1.25 & 1.18 & 2.43 & -0.87 & 0.53 & 1.39 \\
\hline IIIB & $M$ & 5.1 & 9.3 & 4.2 & 0.19 & 0.27 & 0.08 & 0.90 & 1.40 & 0.50 & -0.57 & 0.51 & 1.08 \\
\hline$\| I \mathrm{~B}$ & $M$ & 4.2 & 6.8 & 2.6 & 0.44 & 0.24 & -0.20 & 2.07 & 1.38 & -0.69 & -0.19 & -0.63 & -0.44 \\
\hline IIIB & $M$ & 1.8 & 3.7 & 1.9 & -0.98 & 1.11 & 2.09 & 4.08 & 4.76 & 0.68 & -0.48 & 0.41 & 0.89 \\
\hline Mean & & 4.4 & 12.4 & 8.0 & -0.39 & 0.59 & 0.98 & 1.32 & 3.36 & 2.04 & 0.13 & 0.24 & 0.11 \\
\hline
\end{tabular}

MPS Mucopolysaccharidosis, LVMI Left ventricular mass index, IVSd Interventricular septal end-diastolic dimension, LVPWd Left ventricular posterior wall end-diastolic dimension 


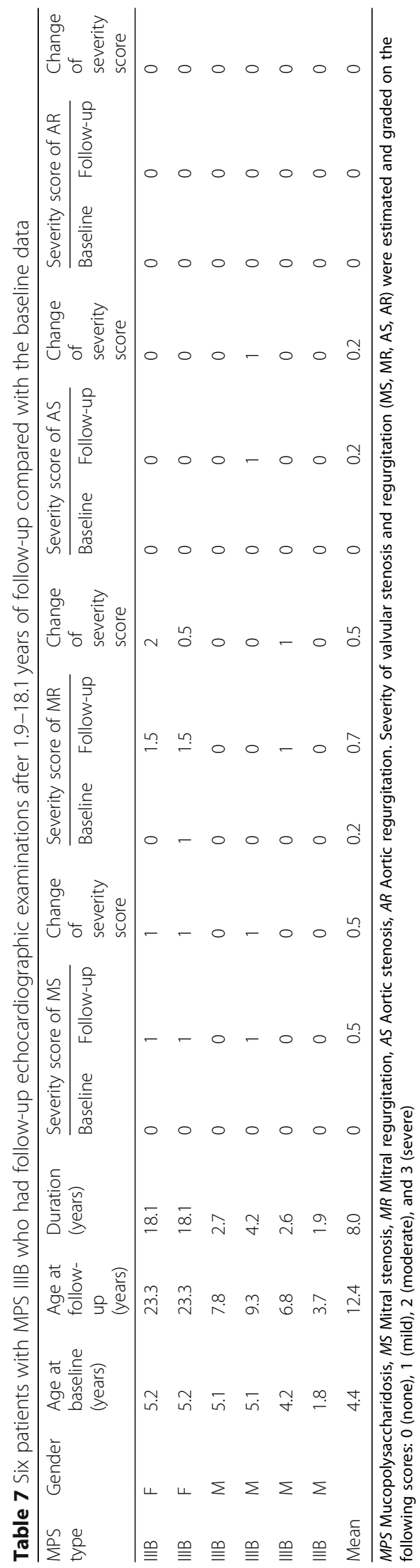




\section{Conclusion}

Cardiac involvement in MPS III is less common and milder compared with the other types of MPS. In this study, a substantial proportion of the patients with MPS III had aortic dilatation, increased interventricular septum thickness, and mild valvular heart disease. Our six MPS IIIB patients had worse valvular heart disease and cardiac hypertrophy according to echocardiographic examinations performed after 1.9-18.1 years of follow-up. The aortic valve abnormalities and valvular stenosis in these patients worsened with increasing age, which is consistent with the progressive nature of this disease. Thus, it is crucial to make an early diagnosis through screening programs for high-risk populations or newborns in order to initiate ERT or gene therapy before the occurrence of irreversible cardiac damage to improve the clinical outcome. These findings and follow-up data can also be used to develop quality of care strategies for such patients.

\section{Abbreviations \\ AR: Aortic regurgitation; AS: Aortic stenosis; ASH: Asymmetric septal hypertrophy; E/A: Ratio between early and late (atrial) ventricular filling velocity; ECG: Electrocardiography; ERT: Enzyme replacement therapy; GAGs: Glycosaminoglycans; IVSd: Interventricular septal end-diastolic dimen- sion; IVSs: Interventricular septal end-systolic dimension; LAD: Left atrial dimension; LV: Left ventricular; LVIDd: Left ventricular end-diastolic dimen- sion; LVIDs: Left ventricular end-systolic dimension; LVMI: Left ventricular mass index; LVPWd: Left ventricular posterior wall end-diastolic dimension; LVPWs: Left ventricular posterior wall end-systolic dimension; MPS: Mucopolysaccharidosis; MR: Mitral regurgitation; MS: Mitral stenosis; NAGLU: Alpha-N-acetylglucosaminidase; RVDd: Right ventricular end-diastolic dimension}

\section{Acknowledgements}

We acknowledge the participation of study patients and their families. This study was supported by research grants from the Ministry of Science and Technology, Executive Yuan, Taiwan (MOST-106-2314-B-195-015-MY2, MOST105-2628-B-195-001-MY3, and MOST-105-2314-B-195-013) and Mackay Memorial Hospital (MMH-E-108-16, MMH-101-111, MMH-103-092 and MMH-10782). The authors thank Ms. Tsai-Feng Ho for her professional assistance in biostatistics.

\section{Authors' contributions}

HYL performed acquisition, statistical analysis and interpretation of data, and drafting of the manuscript. SPL and CKC participated in design of the study, interpretation of the data and helped to draft the manuscript. MRC, SML, $\mathrm{CLH}, \mathrm{DMN}$, and TMC were responsible for patient screening and revised the manuscript. All authors read and accepted the manuscript.

\section{Funding}

This study was supported by research grants from the Ministry of Science and Technology, Executive Yuan, Taiwan (MOST-106-2314-B-195-015-MY2, MOST-105-2628-B-195-001-MY3, and MOST-105-2314-B-195-013) and Mackay Memorial Hospital (MMH-E-108-16, MMH-101-111, MMH-103-092 and MMH107-82). The authors confirm independence from the sponsors. The contents of the article, including the design of the study and collection, analysis, and interpretation of data and in writing the manuscript, have not been influenced by the sponsors.

\section{Availability of data and materials}

Not applicable. There are no other supporting data and materials since all of them are in this article.

\section{Ethics approval and consent to participate}

All procedures followed were in accordance with the ethical standards of the responsible committee on human experimentation (institutional and national) and with the Declaration of Helsinki of 1975, as revised in 2000. The Institutional Review Board of Mackay Memorial Hospital approved this study, and written informed consent was obtained from all of the patients or their parents who were included in the study.

\section{Consent for publication}

Written informed consent for publication was obtained from all of the patients or their parents who were included in the study.

\section{Competing interests}

The authors declare that they have no competing interests

\section{Author details}

${ }^{1}$ Department of Medicine, Mackay Medical College, New Taipei City, Taiwan. ${ }^{2}$ Department of Pediatrics, Mackay Memorial Hospital, No.92, Sec. 2, Chung-Shan North Road, Taipei 10449, Taiwan. ${ }^{3}$ Department of Medical Research, Mackay Memorial Hospital, 92 Chung-Shan N. Rd., Sec. 2, Taipei 10449, Taiwan. ${ }^{4}$ Mackay Junior College of Medicine, Nursing and Management, Taipei, Taiwan. ${ }^{5}$ Department of Medical Research, China Medical University Hospital, China Medical University, Taichung, Taiwan. ${ }^{6}$ Institute of Biomedical Sciences, Mackay Medical College, New Taipei City, Taiwan. ${ }^{7}$ Division of Cardiology, Department of Internal Medicine, Mackay Memorial Hospital, Taipei, Taiwan. ${ }^{8}$ Department of Pediatrics, Taipei Veterans General Hospital, Taipei, Taiwan. ${ }^{9}$ Department of Pediatric Neurology, Changhua Christian Children's Hospital, Changhua, Taiwan. ${ }^{10}$ Department of Biological Science and Technology, College of Biological Science and Technology, National Chiao Tung University, Hsinchu, Taiwan. ${ }^{11}$ College of Medicine, Fu-Jen Catholic University, Taipei, Taiwan. ${ }^{12}$ Department of Infant and Child Care, National Taipei University of Nursing and Health Sciences, Taipei, Taiwan

Received: 19 February 2019 Accepted: 4 June 2019

Published online: 13 June 2019

\section{References}

1. Neufeld EF, Muenzer J: The mucoplysaccharidoses. In: Scriver CR, Beaudet AL, Sly WS, Valle D, eds; Childs B, Kinzler KW, Vogelstein B, assoc, eds. The metabolic and molecular bases of inherited disease, 8th edn. New York: McGraw-Hill; 2001, 3421-3452.

2. Dangel JH. Cardiovascular changes in children with mucopolysaccharide storage diseases and related disorders--clinical and echocardiographic findings in 64 patients. Eur J Pediatr. 1998;157:534-8.

3. Fesslová V, Corti P, Sersale G, Rovelli A, Russo P, Mannarino S, et al. The natural course and the impact of therapies of cardiac involvement in the mucopolysaccharidoses. Cardiol Young. 2009:19:170-8.

4. Mohan UR, Hay AA, Cleary MA, Wraith JE, Patel RG. Cardiovascular changes in children with mucopolysaccharide disorders. Acta Paediatr. 2002;91:799-804

5. Wippermann CF, Beck M, Schranz D, Huth R, Michel-Behnke I, Jüngst BK. Mitral and aortic regurgitation in 84 patients with mucopolysaccharidoses. Eur J Pediatr. 1995;154:98-101.

6. Braunlin EA, Harmatz PR, Scarpa M, Furlanetto B, Kampmann C, Loehr JP, et al. Cardiac disease in patients with mucopolysaccharidosis: presentation, diagnosis and management. J Inherit Metab Dis. 2011;34:1183-97.

7. Leal GN, de Paula AC, Leone C, Kim CA. Echocardiographic study of paediatric patients with mucopolysaccharidosis. Cardiol Young. 2010;20: 254-61

8. Chen MR, Lin SP, Hwang HK, Yu CH. Cardiovascular changes in mucopolysaccharidoses in Taiwan. Acta Cardiol. 2005;60:51-3.

9. Brands MM, Frohn-Mulder IM, Hagemans ML, Hop WC, Oussoren E, Helbing WA, et al. Mucopolysaccharidosis: cardiologic features and effects of enzyme-replacement therapy in 24 children with MPS I, II and VI. J Inherit Metab Dis. 2013;36:227-34.

10. Lin SM, Lin HY, Chuang CK, Lin SP, Chen MR. Cardiovascular abnormalities in Taiwanese patients with mucopolysaccharidosis. Mol Genet Metab. 2014; 111:493-8.

11. Lin HY, Chuang CK, Chen MR, Lin SM, Hung CL, Chang CY, et al. Cardiac structure and function and effects of enzyme replacement therapy in patients with mucopolysaccharidoses I, II, IVA and VI. Mol Genet Metab. 2016;117:431-7 
12. Lin HY, Chen MR, Lin SM, Hung CL, Niu DM, Chuang CK, et al. Cardiac features and effects of enzyme replacement therapy in Taiwanese patients with mucopolysaccharidosis IVA. Orphanet J Rare Dis. 2018;13:148.

13. Braunlin E, Wang R. Cardiac issues in adults with the mucopolysaccharidoses: current knowledge and emerging needs. Heart. 2016;102:1257-62

14. Braunlin EA, Berry JM, Whitley CB. Cardiac findings after enzyme replacement therapy for mucopolysaccharidosis type I. Am J Cardiol. 2006 98:416-8.

15. Jones SA, Almássy Z, Beck M, Burt K, Clarke JT, Giugliani R, et al. Mortality and cause of death in mucopolysaccharidosis type II-a historical review based on data from the hunter outcome survey (HOS). J Inherit Metab Dis. 2009:32:534-43

16. Lavery C, Hendriksz C. Mortality in patients with Morquio syndrome A. JIMD Rep. 2015;15:59-66.

17. Lin HY, Chuang CK, Huang YH, Tu RY, Lin FJ, Lin SJ, et al. Causes of death and clinical characteristics of 34 patients with Mucopolysaccharidosis II in Taiwan from 1995-2012. Orphanet J Rare Dis. 2016;11:85.

18. Lin HY, Lin SP, Chuang CK, Chen MR, Chen BF, Wraith JE. Mucopolysaccharidosis I under enzyme replacement therapy with laronidase--a mortality case with autopsy report. J Inherit Metab Dis. 2005: 28:1146-8.

19. Fedele AO. Sanfilippo syndrome: causes, consequences, and treatments. Appl Clin Genet. 2015:8:269-81.

20. Delgadillo V, O'Callaghan Mdel M, Gort L, Coll MJ, Pineda M. Natural history of Sanfilippo syndrome in Spain. Orphanet J Rare Dis. 2013;8:189.

21. Lin HY, Chuang CK, Lee CL, Tu RY, Lo YT, Chiu PC, et al. Mucopolysaccharidosis III in Taiwan: natural history, clinical and molecular characteristics of 28 patients diagnosed during a 21-year period. Am J Med Genet A. 2018:176A:1799-809.

22. Wilhelm CM, Truxal KV, McBride KL, Kovalchin JP, Flanigan KM. Natural history of echocardiographic abnormalities in mucopolysaccharidosis III. Mo Genet Metab. 2018;124:131-4

23. Nijmeijer SCM, de Bruin-Bon RHACM, Wijburg FA, Kuipers IM. Cardiac disease in mucopolysaccharidosis type III. J Inherit Metab Dis. 2019;42: 276-85.

24. Ribeiro EM, Brusius-Facchin AC, Leistner-Segal S, da Silva CA, Schwartz IV. Cardiac disease as the presenting feature of mucopolysaccharidosis type IIIA: a case report. Mol Genet Metab Rep. 2014;1:422-4.

25. Muenzer J, Beekman RH, Profera LM, Bove EL. Severe mitral insufficiency in mucopolysaccharidosis type III-B (Sanfilippo syndrome). Pediatr Cardiol. 1993;14:130-2.

26. Schiattarella GG, Cerulo G, De Pasquale V, Cocchiaro P, Paciello O, Avallone $\mathrm{L}$, et al. The murine model of mucopolysaccharidosis IIIB develops cardiopathies over time leading to heart failure. PLoS One. 2015;10: e0131662.

27. Chuang CK, Lin SP, Lin SJ, Wang TJ. MPS screening methods, the Berry spot and acid turbidity tests, cause a high incidence of false-negative results in sanfilippo and morquio syndromes. J Clin Lab Anal. 2002;16:253-8.

28. Chuang CK, Lin HY, Wang TJ, Tsai CC, Liu HL, Lin SP. A modified liquid chromatography/tandem mass spectrometry method for predominant disaccharide units of urinary glycosaminoglycans in patients with mucopolysaccharidoses. Orphanet J Rare Dis. 2014:9:135.

29. Lang RM, Badano LP, Mor-Avi V, Afilalo J, Armstrong A, Ernande L, et al. Recommendations for cardiac chamber quantification by echocardiography in adults: an update from the American Society of Echocardiography and the European Association of Cardiovascular Imaging. Eur Heart J Cardiovasc Imaging. 2015;16:233-70

30. Einarsen E, Cramariuc D, Lønnebakken MT, Boman K, Gohlke-Bärwolf C, Chambers JB, et al. Comparison of frequency of ischemic cardiovascular events in patients with aortic stenosis with versus without asymmetric septal hypertrophy (from the SEAS trial). Am J Cardiol. 2017;119:1082-7.

31. Eidem BW, McMahon CJ, Cohen RR, Wu J, Finkelshteyn I, Kovalchin JP, et al. Impact of cardiac growth on Doppler tissue imaging velocities: a study in healthy children. J Am Soc Echocardiogr. 2004;17:212-21.

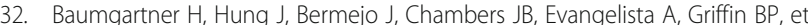
al. Echocardiographic assessment of valve stenosis: EAE/ASE recommendations for clinical practice. J Am Soc Echocardiogr. 2009;22:1-23 quiz 101-102.

33. Lancellotti P, Tribouilloy C, Hagendorff A, Popescu BA, Edvardsen T, Pierard $L A$, et al. Recommendations for the echocardiographic assessment of native valvular regurgitation: an executive summary from the European Association of Cardiovascular Imaging. Eur Heart J Cardiovasc Imaging. 2013;14:611-44

34. Lang RM, Bierig M, Devereux RB, Flachskampf FA, Foster E, Pellikka PA, et al. Recommendations for chamber quantification: a report from the American Society of Echocardiography's guidelines and standards committee and the chamber quantification writing group, developed in conjunction with the European Association of Echocardiography, a branch of the European Society of Cardiology. J Am Soc Echocardiogr. 2005;18:1440-63.

35. Kampmann C, Wiethoff CM, Wenzel A, Stolz G, Betancor M, Wippermann CF et al. Normal values of $\mathrm{M}$ mode echocardiographic measurements of more than 2000 healthy infants and children in central Europe. Heart. 2000;83: $667-72$

36. Foster BJ, Mackie AS, Mitsnefes M, Ali H, Mamber S, Colan SD. A novel method of expressing left ventricular mass relative to body size in children. Circulation. 2008;117:2769-75.

37. Lin HY, Lee CL, Lo YT, Wang TJ, Huang SF, Chen TL, et al. The relationships between urinary glycosaminoglycan levels and phenotypes of mucopolysaccharidoses. Mol Genet Genomic Med. 2018;6:982-92.

38. Bolourchi M, Renella P, Wang RY. Aortic root dilatation in mucopolysaccharidosis I-VII. Int J Mol Sci. 2016;17(12):2004.

39. Kato R, Miyahara H, Kawano T, Matsuzuka A, Noda K, Izumi T. Heparan sulfate storage in the cardiac conduction system triggers atrioventricular block. Brain and Development. 2017;39:418-21.

40. Kampmann C, Beck M, Morin I, Loehr JP. Prevalence and characterization of cardiac involvement in hunter syndrome. J Pediatr. 2011;159:327-331.e2.

41. Konstam MA, Kramer DG, Patel AR, Maron MS, Udelson JE. Left ventricular remodeling in heart failure: current concepts in clinical significance and assessment. JACC Cardiovasc Imaging. 2011;4:98-108.

42. Al-Sannaa NA, Bay L, Barbouth DS, Benhayoun Y, Goizet C, Guelbert N, et al. Early treatment with laronidase improves clinical outcomes in patients with attenuated MPS I: a retrospective case series analysis of nine sibships. Orphanet J Rare Dis. 2015:10:131

43. Lin SP, Lin HY, Wang TJ, Chang CY, Lin CH, Huang SF, et al. A pilot newborn screening program for mucopolysaccharidosis type I in Taiwan. Orphanet J Rare Dis. 2013;8:147.

44. Chuang CK, Lin HY, Wang TJ, Huang YH, Chan MJ, Liao HC, et al. Status of newborn screening and follow up investigations for mucopolysaccharidoses I and || in Taiwan. Orphanet J Rare Dis. 2018;13:84

45. Chan MJ, Liao HC, Gelb MH, Chuang CK, Liu MY, Chen HJ, et al. Taiwan National Newborn Screening Program by tandem mass spectrometry for mucopolysaccharidoses types I, II, and VI. J Pediatr. 2019;205:176-82.

46. Colón C, Alvarez JV, Castaño C, Gutierrez-Solana LG, Marquez AM, O'Callaghan $\mathrm{M}$, et al. A selective screening program for the early detection of mucopolysaccharidosis: results of the FIND project - a 2-year follow-up study. Medicine (Baltimore). 2017;96:e6887.

\section{Publisher's Note}

Springer Nature remains neutral with regard to jurisdictional claims in published maps and institutional affiliations.

Ready to submit your research? Choose BMC and benefit from:

- fast, convenient online submission

- thorough peer review by experienced researchers in your field

- rapid publication on acceptance

- support for research data, including large and complex data types

- gold Open Access which fosters wider collaboration and increased citations

- maximum visibility for your research: over $100 \mathrm{M}$ website views per year

At BMC, research is always in progress.

Learn more biomedcentral.com/submissions 